\title{
A Comparative Analysis of Public Cloud Platforms and Introduction of Multi-Cloud
}

\author{
Aditi Rajan Khot \\ Dept. EXTC \\ SIES, Graduate School of Technology \\ (University of Mumbai) \\ Navi Mumbai, India
}

\begin{abstract}
Cloud computing is an accepted widely, emerging paradigm for its 'pay as you go' approach, massive economies of scale, and global in minutes concept. Over the years, different cloud providers have emerged with various services to meet the requirements of the end-user. Because of an increase in the diversity of services, the complexity increases. Customers cannot decide the optimal service to fulfill their requirements. This paper provides a comparative analysis of services of top public cloud providers namely, AWS, GCP, Oracle, and Microsoft Azure. Public cloud-provider strives to be efficient in every technological aspect, though some are better for certain tasks than others. This paper, as a solution, introduces the concept of Multi-Cloud computing, to leverage the benefits of the different cloud providers and to maximize their utility in single network architecture.
\end{abstract}

Keywords:- Cloud Computing, Compute, Cloud Service Providers, AWS, GCP, Oracle, Microsoft Azure, Comparative Analysis, Multi-Cloud Computing.

\section{INTRODUCTION}

Cloud Service Providers are organizations that provide cloud computing services to customers. They are third-party companies with infrastructure, storage, servers, data management, and business applications that connected via secure private networking, the internet. The significant rise of public clouds and services provides great efficiency and on-demand scalability.

Amazon Web Services, AWS launched in July 2003, was the first cloud computing service that started offering infrastructure as a service in late 2008, since then it's ceaselessly emerging as the highest competitive and market-oriented cloud platform [19]. Around 175 products, services, and its firstly introduced a pay-as-go strategy, AWS has attracted private organizations, businesses, and individuals around the globe. It was the first cloud to expand beyond compute and storage and introduce ARM processors in data centers.

Azure, rising from its footprints of software as a service, launch the preview version of Azure in February 2010. Initially, Azure argued to be adverse with AWS. However, Azure improved by adding a variety of languages, frameworks, and unexpectedly, Linux. Azure is a plausible choice regardless of organizations that don't use
Windows servers [20]. Azure has globally more regions across the world than any other cloud provider, which is a digital transformation with edge-cutting efforts.

Google announced in April 2008 a platform as a service for developing web applications with Googleadministered data centers. The service has become available since November 2011 and consequently added various services to the cloud. Google believes that business still runs on-premise and enterprises are hesitant to move on-premise. Instead of focusing on virtual servers like AWS and Azure, GCP offers relational database engines, data storage, and automated deployment services that assist enterprises to shift easily to the cloud.

In the mid-90s, Oracle deployed applications to the internet browser. The off-premise service named as "Oracle Outsourcing" in 2002 and later in 2004 as "On Demand." In 2008, "Cloud Computing" became an acceptable name. Oracle is renowned for its SaaS, PaaS, IaaS, and database, which is autonomous innovatively. Though for enterprises Oracle supports the SaaS applications [20] and introduces the concept of autonomous cloud.

In 2020, Cloud computing is more sophisticated, multi-cloud, and expected to focus on sales as the best vendors contest for market share. Fig. 1 shows the public cloud adoptions and the expected usage percentage [16]. Selecting the relevant cloud service provider is difficult and the universal answer by all enterprise is it depends on the workflow, which to an extension is true. Whether it's Amazon AWS, Google Cloud, and Microsoft Azure for their IaaS or Dell, Hewlett-Packard, IBM, and VMware in hybrid deployments, enterprises are supporting various options. SAP, Salesforce, Adobe, Ditto for software as a service, while Oracle and SAP for the database as a service.

This paper aims at introducing Cloud computing and the comparison of top public cloud providers. It bases the comparison of cloud service providers on computing, storage, and databases. Insight into various security and management services. The enterprises can differentiate the cloud that matches best with their business workflow. Though, users tend to use various services from the different public clouds, hence as a solution to introduce multi-cloud service. 


\section{BACKGROUND}

This section provides an insight into the definition of cloud computing, primary types of service models offered and deployment strategies utilized in cloud computing

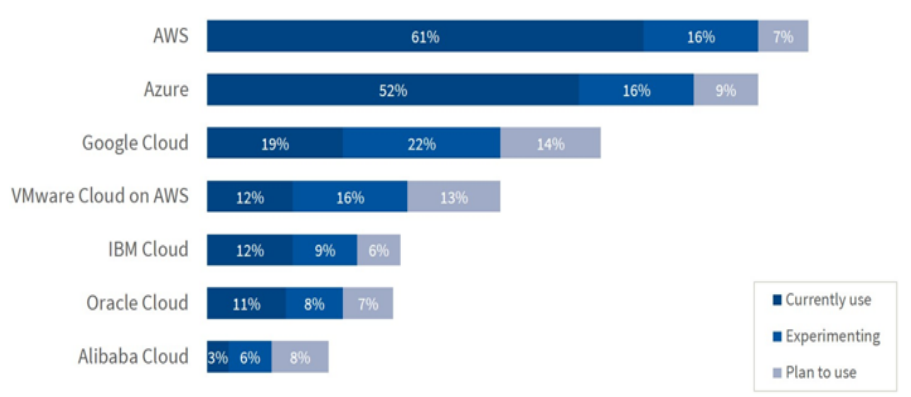

Fig 1:- Public Cloud Adoptions

Source: RightScale 2019 State of the Cloud Report from Flexra.

\section{A. Cloud Computing}

The National Institute of Standards and Technology (NIST) US, defines cloud computing as a "model for granting users access to a shared pool of configurable computational resources including networks, servers, storage, applications, and services that can be rapidly provisioned (adapted for new services) with little management or service provider interaction" [1]. Internetbased shared processing of data and resources on independent remote servers, encouraging business enterprises to trade off their capital expenditure over operational expenditure [2].

\section{B. Sevice Models}

Traditionally cloud providers deliver three service models Software as a Service (SAAS), Platform as a Service (PASS), Infrastructure as a Service (IAAS) [3], but with the advancement of the specific necessity of the customer, it varies accordingly, concerning cloud providers.

Infrastructure as a Service (IaaS): IaaS, which primarily forms the most popular yet traditional service of cloud computing incorporates, networking, storage, servers, and virtualization. Large business enterprises opt for IaaS, which forms the foundation of cloud computing. Examples of IaaS are Amazon EC2, Google's Compute Engine (GCE), Azure, and Oracle Bare Metal servers.

Storage as a Service (STaaS): Storage as a Service [4] provides chunks of storage in remote infrastructure, and customers pay on usage, frequency to access. Supplementary facilities such as autoscaling, backup's, processing can charge additionally, while storage being the prior usage. Examples of STaaS are Amazon S3, Microsoft OneDrive, and Google Cloud Storage.
Platform as a Service (PaaS): PaaS grants customers, creating-developing-deploying kind of environment. Customers need not worry about the underlying infrastructure but their consequent application and data. Examples of PaaS are Amazon Elastic Beanstalk, Microsoft App Service, and Google's App Engine.

Data as a Service (DaaS): DaaS [5] extends STaaS, particularly concerning the database, or tabular data storage, wherein data is not only limited to storage and access but can be processed, perform analytics, migration, and various other functions. Examples of DaaS Amazon DynamoDB, Microsoft SQL Database, GCP's Datastore, and Oracle's Data Cloud.

Function as a Service (FaaS): FaaS is a micro-service, a comprehensive abstraction of infrastructure enables consumers to run functions, event-driven action, or a logic. Functions are triggered, and customers pay until the code runs [6]. Oracle Cloud Fn, Google Cloud Functions, AWS Lambda, and Microsoft Azure Functions are applications of FaaS.

Software as a Service (SAAS): SaaS is a pre-built software version of the application, and customers must subscribe to a software license. SaaS is the only service model wherein the customers have practically no developing options at the backend, they solely use the pre-defined software provided to them. Examples of SaaS are GSuite and Office365.

C. Deployment Models

$>$ Public cloud: Public cloud is owned by cloud service providers, available to various organizations. The infrastructure remains identical for all general consumers across the globe, while consumers connect via a reliable network connection [7]. The most popular deployment model and cost-effective for its pay-as-youuse subscription, opted by consumers.

Private Cloud: A private cloud is entirely operated by a single organization or a third party enterprise. The complete infrastructure, data center, networking, and operations in the cloud are confined only to the private organization. The owner is responsible for the investment, management, and maintenance of the cloud.

> Hybrid Cloud: The hybrid cloud from the name combines public and private clouds to leverage dual benefits. Often termed as 'cloud-bursting' simply means extending on the public cloud to meet the outrageous demands of the business, in case the private cloud is inefficient. It allows applications to run in the most suitable region. Hybrid Cloud shares ownership between both private organizations and cloud service providers. 


\section{COMPARISION OF PUBLIC CLOUD PLATFORM}

\section{A. Compute Services}

Compute services allow customers to carry out computational capabilities by following instructions and deploying applications without worrying about the underlying hardware [15].

AWS Compute: AWS renowned computing service is Elastic Cloud Computing, called as EC2 [8]. AWS EC2 is highly scalable, secure, and eliminates the investment of the hardware allowing, customers to focus on deploying and developing applications. EC2 supports Windows, Linux, GPU, HPC, object storage, and all services clubbed together under the name of Elastic Cloud Computing [9]. AWS Fargate which is serverless computing works efficiently for both containers and Kubernetes. Table 1 shows a comparison of various computing services.

> Microsoft Compute: Azure is primarily known for its virtual machines, and supports Linux, IBM, Oracle, SQL Server, and SAP workflow. Like AWS, it has a catalog of services that are optimized with machine learning and artificial Intelligence [10].

> Google Compute: It has comparatively less compute services than other providers. Though, have pre-defined and custom servers that are billed per-second. Sustainably, it supports carbon-efficient infrastructure and uses less energy in their data centers. Google cloud originally introduced Kubernetes [11], container orchestration that have gained immense popularity among various cloud providers.

$>$ Oracle Compute: OCI despite being a newcomer in cloud marketing yet can provide all compute services [12] for its strong Infrastructure as a service. It has a small marketing share, but the pricing model is considered lower than AWS [18].

\section{B. Storage and Databases}

AWS, Oracle, and GCP have automatic versioning which is currently missing in Azure. However, Data Lake service offers an additional feature to run a massive amount of analytics workloads. Other cloud providers have better backup options than AWS Glacier. Oracle is known best for its autonomous DBaaS. Every cloud provider has NoSQL, relational, and petabyte-scale data warehousing. Oracle has advanced managed databases. Oracle has an extended model that is object-relational, making complex business data into a relational database [14].

The storage is relatively cheaper in all cloud providers and cheapest in Oracle as no ingress charge irrespective of the region. Eventually, charges can spike if versioning, the amount of data is altered. Table 2 shows a comparison of storage and database between various cloud providers.

\section{Networking Sevices}

AWS is generally accepted for its workloads, running under completely locked networking environments. The networking architecture of AWS is more or less matched with the Oracle cloud. However, all the rest providers offer similar and effective decor of capabilities. There are few significant variations such as AWS managed web Application Firewall and Azure's platform as a service networking support [17]. Essentially networking forms the least comparative factor to choose as every cloud.

\section{Security and Management Services}

AWS, Azure has a wide range of management and monitoring tools while GCP and Oracle are still in progress. Oracle provides Desktop Visualization for its Autonomous Database [13] while for general cloud services the options are fairly average than AWS, Azure, and GCP. Despite every cloud's efforts to provide optimal security, all public clouds claim that cloud security is a shared responsibility, which states that "we are responsible for the security of the cloud, you are responsible for security in the cloud." Table 4 shows a comparison of security and management services.

\begin{tabular}{|c|c|c|c|c|}
\hline \multirow{2}{*}{$\begin{array}{l}\text { Compute } \\
\text { Services }\end{array}$} & \multicolumn{4}{|c|}{ Comparison of compute services: AWS vs. GCP vs. Microsoft Azure vs. OCI } \\
\hline & AWS & GCP & Azure & OCI \\
\hline Bare Metal & $\begin{array}{l}\text { Amazon EC2 Bare } \\
\text { Metal Instance }\end{array}$ & Bare Metal Servers & $\begin{array}{c}\text { Azure Bare Metal } \\
\text { Servers }\end{array}$ & Bare Metal Instance \\
\hline $\begin{array}{c}\text { Dedicated } \\
\text { Virtual Host }\end{array}$ & $\begin{array}{c}\text { Amazon EC2 Dedicated } \\
\text { Host }\end{array}$ & Sole-tenant node & Azure Dedicated Host & Dedicated virtual Host \\
\hline Virtual Machine & Amazon EC2 & $\begin{array}{l}\text { Compute Engine: Multi- } \\
\text { tenant node }\end{array}$ & Azure Virtual Machine & Oracle Virtual Machines \\
\hline Severless & $\begin{array}{c}\text { Lambda } \\
\text { AWS Fargate }\end{array}$ & GCP Functions & $\begin{array}{c}\text { Azure Functions } \\
\text { Azure Service Fabric } \\
\text { Event Grid }\end{array}$ & Oracle Functions \\
\hline Containers & $\begin{array}{l}\text { Amazon EC2 } \\
\text { Containers }\end{array}$ & Container Registry & Azure Containers & OCI Container Registry \\
\hline Batch & AWS Batch & Preempticle VM & Azure Batch & - \\
\hline $\begin{array}{c}\text { Container } \\
\text { Orchestration }\end{array}$ & $\begin{array}{c}\text { Amazon Elastic } \\
\text { Kubernetes Service } \\
\text { EC2 Container Service }\end{array}$ & Kubernetes Engine & $\begin{array}{c}\text { Azure Kubernetes } \\
\text { Service }\end{array}$ & $\begin{array}{l}\text { Oracle Kubernetes } \\
\text { Engine }\end{array}$ \\
\hline PaaS & Amazon Lightsail & - & App Service & - \\
\hline
\end{tabular}

Table 1:- Comparision of Networking Services 
ISSN No:-2456-2165

\begin{tabular}{|c|c|c|c|c|}
\hline \multirow{2}{*}{$\begin{array}{l}\text { Storage and } \\
\text { Database } \\
\text { Services }\end{array}$} & \multicolumn{4}{|c|}{ Comparison of storage and database services: AWS vs. GCP vs. Microsoft Azure vs. OCI } \\
\hline & AWS & GCP & Azure & OCI \\
\hline Storage & $\begin{array}{l}\text { Simple Storage Service } \\
\text { Elastic Block Storage } \\
\text { Elastic File System }\end{array}$ & $\begin{array}{l}\text { Cloud Storage } \\
\text { Persistent Disk } \\
\text { Filestore } \\
\end{array}$ & $\begin{array}{l}\text { Blob Storage } \\
\text { Disk Storage } \\
\text { File Storage }\end{array}$ & $\begin{array}{l}\text { Object Storage } \\
\text { Block Storage } \\
\text { OCI File Storage }\end{array}$ \\
\hline Archive storage & Amazon Glacier & $\begin{array}{l}\text { Archival Storage } \\
\text { Cloud Storage }\end{array}$ & $\begin{array}{c}\text { Azure Cool Storage } \\
\text { Azure Archive Storage }\end{array}$ & Archive Storage \\
\hline Storage Gateway & Storage Gateway & 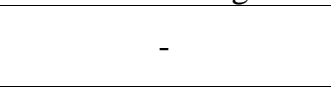 & Azure StorSimple & $\begin{array}{c}\text { Storage Software } \\
\text { Appliance }\end{array}$ \\
\hline $\begin{array}{l}\text { Relational } \\
\text { Database }\end{array}$ & $\begin{array}{c}\text { Relational Database } \\
\text { Service(RDS) } \\
\text { AWS Aurora }\end{array}$ & $\begin{array}{l}\text { Cloud Spanner } \\
\text { Cloud SQL }\end{array}$ & $\begin{array}{c}\text { Azure SQL } \\
\text { Azure MySQL } \\
\text { Azure PostgresSQL } \\
\text { SQL DB Edge } \\
\text { SQL server Stretch DB }\end{array}$ & $\begin{array}{c}\text { Oracle MySQL } \\
\text { DBaaS }\end{array}$ \\
\hline $\begin{array}{l}\text { Non-Relational } \\
\text { Database }\end{array}$ & $\begin{array}{l}\text { AWS DynamoDB } \\
\text { AWS DynamoDB } \\
\text { Accelerator }\end{array}$ & $\begin{array}{l}\text { Cloud Bigtable } \\
\text { Cloud Firestore } \\
\text { Cloud Datastore } \\
\end{array}$ & $\begin{array}{c}\text { CosmosDB } \\
\text { Time Series Insights } \\
\text { Tabel Storage }\end{array}$ & Oracle NoSQL DB \\
\hline $\begin{array}{l}\text { In-memory Data } \\
\text { store }\end{array}$ & ElastiCache & $\begin{array}{c}\text { Memorystore } \\
\text { Firebase Realtime DB }\end{array}$ & RedisCache & ( \\
\hline Data Warehouse & RedShift & BigQuery & $\begin{array}{l}\text { Synapse Analytics } \\
\text { Data Lake }\end{array}$ & $\begin{array}{c}\text { Autonomous Exadata } \\
\text { Autonomous } \\
\text { Data Warehouse }\end{array}$ \\
\hline Data Migration & $\begin{array}{l}\text { AWS DB Migration } \\
\text { AWS Import/Export } \\
\text { AWS Snowball } \\
\text { Snowball Edge } \\
\text { AWS Snowmobile }\end{array}$ & $\begin{array}{c}- \\
- \\
- \\
\text { Transfer Appliance } \\
\end{array}$ & $\begin{array}{c}\text { Azure DB Migration } \\
\text { Azure Import/Export } \\
- \\
\text { Azure Data Box } \\
-\end{array}$ & $\begin{array}{c}\text { DB Cloud Migration } \\
\text { Data Transfer Service } \\
\text { Data Transfer Appliance } \\
\text { Data Transfer Appliance } \\
\text { - }\end{array}$ \\
\hline
\end{tabular}

Table 2:- Comparision of Networking Services

\begin{tabular}{|c|c|c|c|c|}
\hline \multirow{2}{*}{$\begin{array}{l}\text { Network } \\
\text { services }\end{array}$} & \multicolumn{4}{|c|}{ Comparison of network services: AWS vs. GCP vs. Microsoft Azure vs. OCI } \\
\hline & AWS & GCP & Azure & OCI \\
\hline $\begin{array}{l}\text { Virtual } \\
\text { Networking }\end{array}$ & $\begin{array}{c}\text { Amazon Virtual Private } \\
\text { Cloud }\end{array}$ & $\begin{array}{l}\text { GCP Virtual Private } \\
\text { Cloud }\end{array}$ & Azure Virtual Network & $\begin{array}{c}\text { Oracle Virtual Cloud } \\
\text { Network }\end{array}$ \\
\hline $\begin{array}{l}\text { Content Delivery } \\
\text { Network(CDN) }\end{array}$ & Amazon CloudFront & GCP CDN & Azure CDN & - \\
\hline $\begin{array}{l}\text { Domain Name } \\
\text { System (DNS) }\end{array}$ & Route 53 & GCP DNS & Azure DNS & Oracle DNS \\
\hline $\begin{array}{l}\text { Cross-Premises } \\
\text { Networking }\end{array}$ & $\begin{array}{l}\text { Amazon Virtual Private } \\
\text { Network(VPN) }\end{array}$ & Cloud VPN & VPN Gateway & VPN Connect \\
\hline $\begin{array}{l}\text { Dedicate Private } \\
\text { network gateway }\end{array}$ & $\begin{array}{l}\text { Direct Connect gateway } \\
\text { AWS Private Link }\end{array}$ & Cloud InterConnect & Express Route & Fast Connect \\
\hline $\begin{array}{l}\text { Global Traffic } \\
\text { Management }\end{array}$ & Rout 53 Traffic Flow & - & Traffic Manager & Traffic Management \\
\hline Cross Cloud & AWS Outposts & GCP Anthos & Azure Arc & $\begin{array}{c}\text { Oracle } \\
\text { Cloud@Customers }\end{array}$ \\
\hline Load Balancing & Elastic Load Balancer & Cloud Load Balancer & Azure Load Balancer & Oracle Load Balancer \\
\hline
\end{tabular}

Table 3:- Comparision of Networking Services 
ISSN No:-2456-2165

\begin{tabular}{|c|c|c|c|c|}
\hline \multirow{2}{*}{$\begin{array}{c}\text { Security and } \\
\text { Management } \\
\text { services }\end{array}$} & \multicolumn{4}{|c|}{ Comparison of security and management services: AWS vs. GCP vs. Microsoft Azure vs. OCI } \\
\hline & AWS & GCP & Azure & OCI \\
\hline $\begin{array}{l}\text { Authentication } \\
\text { and } \\
\text { Authorization }\end{array}$ & $\begin{array}{c}\text { Identity and Access } \\
\text { Management (IAM) } \\
\text { AWS Microsoft manage } \\
\text { Directory } \\
\text { AWS Certificate Manager }\end{array}$ & $\begin{array}{c}\text { Cloud IAM } \\
\text { Identity-Aware Proxy } \\
\text { App Service Certificates }\end{array}$ & Azure Active Directory & Oracle Identity \\
\hline $\begin{array}{l}\text { Key and } \\
\text { Compliance } \\
\text { Management }\end{array}$ & $\begin{array}{c}\text { AWS Key Management } \\
\text { AWS CloudHSM } \\
\text { AWS Secrets Manager } \\
\text { AWS Artifact } \\
\text { AWS Config }\end{array}$ & $\begin{array}{l}\text { Cloud Key Management } \\
\text { Security Command Center }\end{array}$ & $\begin{array}{l}\text { Azure Key Vault } \\
\text { Azure Security and } \\
\text { Compliance }\end{array}$ & $\begin{array}{l}\text { OCI Key management } \\
\text { Oracle Key Vault } \\
\text { Oracle Cloud } \\
\text { compliance } \\
\text { OCI management } \\
\text { Solutions }\end{array}$ \\
\hline Cloud Security & $\begin{array}{c}\text { Guard Duty } \\
\text { Amazon Inspector }\end{array}$ & $\begin{array}{l}\text { Cloud Security Command } \\
\text { Center }\end{array}$ & Azure Security Center & $\begin{array}{l}\text { Oracle Identity:On- } \\
\text { demand }\end{array}$ \\
\hline $\begin{array}{l}\text { Network } \\
\text { Security }\end{array}$ & $\begin{array}{l}\text { AWS Shield } \\
\text { WAF }\end{array}$ & Cloud Armor & Azure DDoS & $\begin{array}{c}\text { Oracle DDos and Traffic } \\
\text { Management } \\
\text { WAF }\end{array}$ \\
\hline $\begin{array}{c}\text { Cloud } \\
\text { Management }\end{array}$ & Elastic BeanStalk & $\begin{array}{l}\text { Cloud Deployment } \\
\text { Manager } \\
\text { Resource Manager }\end{array}$ & $\begin{array}{l}\text { Azure Operational } \\
\text { Insights } \\
\text { Azure Building Blocks } \\
\text { Azure Resource } \\
\text { Manager }\end{array}$ & $\begin{array}{c}\text { Oracle Cloud } \\
\text { Management Solutions } \\
\text { OCI Stack Manager }\end{array}$ \\
\hline $\begin{array}{l}\text { Cloud } \\
\text { Management } \\
\text { Tools }\end{array}$ & $\begin{array}{l}\text { AWS Management } \\
\text { Console } \\
\text { AWS CLI }\end{array}$ & $\begin{array}{l}\text { Cloud Shell } \\
\text { Cloud Console } \\
\text { Cloud APIs }\end{array}$ & $\begin{array}{c}\text { Azure Portal } \\
\text { Azure Powershell } \\
\text { Azure Cloud Shell } \\
\text { Azure CLI }\end{array}$ & $\begin{array}{c}\text { OCI CLI } \\
\text { Oracle Console } \\
\text { API Catalog }\end{array}$ \\
\hline Monitoring & $\begin{array}{l}\text { AWS CloudWatch } \\
\text { AWS CloudTrail } \\
\text { AWS Trusted Advisor }\end{array}$ & $\begin{array}{l}\text { Monitoring } \\
\text { Logging } \\
\text { Cloud Trace } \\
\text { Cloud Debugger } \\
\text { Error Reporting } \\
\text { Operations } \\
\end{array}$ & $\begin{array}{l}\text { Azure Monitor } \\
\text { Azure Advisor }\end{array}$ & $\begin{array}{l}\text { Oracle Application } \\
\text { Performance Monitoring }\end{array}$ \\
\hline
\end{tabular}

Table 4:- Comparision of Security and Management Services

\section{MULTI-CLOUD}

Cloud Computing is strengthening to be more dynamic, based on virtual management both on-premise and off. This raises significant complexity in governance, compliance, self-service, resource management, capacity planning, and financial controls. Every organization ranging from small-scale to enterprise has a varied range of support that they require from cloud vendors shown in Fig. 2. A specific cloud vendor cannot fulfill the customer's precise requirements, leading to unsatisfied business goals, high operational cost, and vendor locked-in [22]. AWS is the eldest and mature cloud provider with large-scale enterprise investment. At its size, it becomes difficult to have close relationships with small vendors, however, some technical consultants can be assigned on additional charges. Azure despite limited Linux varieties has a deep focus on hybrid cloud, and bridge the data center with rapidly scalable Microsoft Azure. AWS specializes in large data transfer while GCP integrates with machine learning capability. Azure and Oracle have dual partnership can benefit small scale business along with widespread regions and autonomous databases.
Multi-cloud termed as "inter clouds" or "cloud-ofclouds" originally introduced by Vukolic [23]. Multi-cloud allows enterprises to select different cloud services from different public cloud providers to leverage collective benefits. Multi-cloud aims to eradicate the reliance on a single cloud provider [24].

Diversity: The supplementary choice of multiple environments gives enterprises flexibility and avoids agent lock-in.

$>$ Fault Tolerance and Proximity: Though every cloud provider's key benefits are to avoid disaster, however, running in multiple clouds gives the customer the highest assurance of high availability. Enterprises can host applications closer to them, in regional public clouds.

> Private Compliance: Multi-cloud helps enterprises accomplish their specific goals by meeting private compliance, governance, and risk management.

> Flexible Pricing Model: In case a business does not commit to one cloud vendor, it is free to select the most affordable cloud vendor or customize its pricing models as per its specifications. 


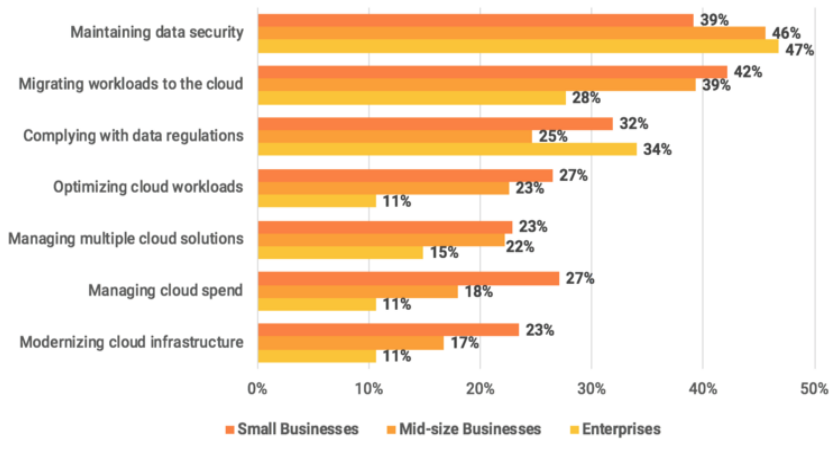

Fig 2:- Top Areas Where Business Need More Support From Cloud Vendors. Source: Spiceworks.

\section{CONCLUSION}

AWS has the most comprehensive services and global reach, in case if the servers are of Windows and Microsoft software, Azure can be the best choice. If a small scale, a web-based startup aiming to scale up fast, GCP is the most appropriate vendor. While inexpensive pricing model, with Oracle software and autonomous databases, Oracle Cloud Infrastructure suits well. The cloud provider should support the business requirements, instead of compromising the business goal in cloud vendor lock-in.

Multi-cloud suggested as a solution, though can add complexity and security concern if left unchecked. It can cause operational management, cost optimization, reporting, and monitoring. Multi-cloud strategy strengths help the organization maintain flexibility and as a stakeholder, it is essential to make the right decision of choosing the management tools, compliance, security, and architecture. It depends essentially depended on the business goal to make the Multi-cloud operate efficiently.

\section{REFERENCES}

[1]. Peter, M., Tim, G.: The NIST Definition of Cloud Computing. Tech. rep., National Institute of Standards and Technology Gaithersburg, MD 20899-8930 and U.S. Department of Commerce (2011)

[2]. T. Antohi, "Model for Cloud Migration Cost," 2019 6th IEEE International Conference on Cyber Security and Cloud Computing (CSCloud)/ 2019 5th IEEE International Conference on Edge Computing and Scalable Cloud (EdgeCom), Paris, France, 2019, pp. 20-28, doi: 10.1109/CSCloud/EdgeCom.2019.00014.

[3]. E. Savolainen, "Cloud service models," in SeminarCloud Computing and Web Services, University of Helsinki, Department of CS, 2012.

[4]. A. Bagaeen, S. Al-Zoubi, R. Al-Sayyed and A. Rodan, "Storage as a Service (STaaS) Security Challenges and Solutions in Cloud Computing Environment: An Evaluation Review," 2019 Sixth HCT Information Technology Trends (ITT), Ras Al Khaimah, United Arab Emirates, 2019, pp. 208-213, doi: 10.1109/ITT48889.2019.9075097.
[5]. O. Terzo, P. Ruiu, E. Bucci and F. Xhafa, "Data as a Service (DaaS) for Sharing and Processing of Large Data Collections in the Cloud," 2013 Seventh International Conference on Complex, Intelligent, and Software Intensive Systems, Taichung, 2013, pp. 475480, doi: 10.1109/CISIS.2013.87.

[6]. P. Castro, V. Ishakian, V. Muthusamy and A. Slominski, "Serverless Programming (Function as a Service)," 2017 IEEE 37th International Conference on Distributed Computing Systems (ICDCS), Atlanta, GA, 2017, pp. 2658-2659, doi: 10.1109/ICDCS.2017.305.

[7]. L. Savu, "Cloud Computing: Deployment Models, Delivery Models, Risks and Research Challenges," 2011 International Conference on Computer and Management (CAMAN), Wuhan, 2011, pp. 1-4, doi: 10.1109/CAMAN.2011.5778816.

[8]. Bermudez, S. Traverso, M. Mellia and M. Munafò, "Exploring the cloud from passive measurements: The Amazon AWS case," 2013 Proceedings IEEE INFOCOM, Turin, 2013, pp. 230-234, doi: 10.1109/INFCOM.2013.6566769.

[9]. G. Juve et al., "Scientific workflow applications on Amazon EC2," 2009 5th IEEE International Conference on E-Science Workshops, Oxford, 2009, pp. 59-66, doi: 10.1109/ESCIW.2009.5408002.

[10]. Microsoft Ai Platform Whitepaper: Build Intelegient Software. (2017). Available: https://azure.microsoft.com/en-in/resources/microsoftai-platform-whitepaper/

[11]. Brendan Burns, Brian Grant, David Oppenheimer, Eric Brewer, John Wilkes, Borg, Omega, and Kubernetes, ACM Queue, vol. 14 (2016), pp. 70. 7093.

[12]. Oracle Cloud Infrastructure Platform Overview, (2020 ), Version 1. Available:https://www.oracle.com/a/ocom/docs/cloud/ oracle-cloud-infrastructure-platform-overview-wp.pdf

[13]. B. Raza, A. Mateen, M. Sher, M. M. Awais and T. Hussain, "Autonomicity in Oracle Database Management System," 2010 International Conference on Data Storage and Data Engineering, Bangalore, 2010, pp. 296-300, doi: 10.1109/DSDE.2010.72.

[14]. Kumar, Sumit \& Chawla, Sunil Kumar \& Bajwa, Manpreet \& Sharma, Himani. (2019). A Comparitive Study of various Cloud Service Platforms.

[15]. Kamal, Muhammad Ayoub \& Raza, Hafiz \& Alam, Muhammad \& Mazliham, M.. (2020). Highlight the Features of AWS, GCP and Microsoft Azure that Have an Impact when Choosing a Cloud Service Provider. 10.35940/ijrte.D8573.018520.

[16]. $2019 \quad$ Flexera, Available: https://resources.flexera.com/web/media/documents/ri ghtscale-2019-state-of-the-cloud-report-fromflexera.pdf

[17]. Dutta, Pranay \& Dutta, Prashant. (2019). Comparative Study of Cloud Services Offered by Amazon, Microsoft and Google. International Journal of Trend in Scientific Research and Development. Volume-3. 981-985. 10.31142/ijtsrd231. 
[18]. R. Aljamal, A. El-Mousa and F. Jubair, "A User Perspective Overview of The Top Infrastructure as a Service and High Performance Computing Cloud Service Providers," 2019 IEEE Jordan International Joint Conference on Electrical Engineering and Information Technology (JEEIT), Amman, Jordan, 2019, pp. 244-249, doi: 10.1109/JEEIT.2019.8717453.

[19]. AWS Well-Architected Framework Publication date: July 2020 (Document Revisions (p. 42)). Available: https://docs.aws.amazon.com/wellarchitected/latest/fr amework/wellarchitected-framework.pdf\#welcome

[20]. S. Ristov and M. Gusev, "Performance vs cost for windows and linux platforms in Windows Azure cloud," 2013 IEEE 2nd International Conference on Cloud Networking (CloudNet), San Francisco, CA, 2013, pp. 214-218, doi: 10.1109/CloudNet.2013.6710581.

[21]. F. M. Elbahri, O. Ismael Al-Sanjary, M. A. M. Ali, Z. Ali Naif, O. A. Ibrahim and M. N. Mohammed, "Difference Comparison of SAP, Oracle, and Microsoft Solutions Based on Cloud ERP Systems: A Review," 2019 IEEE 15th International Colloquium on Signal Processing \& Its Applications (CSPA), Penang, Malaysia, 2019, pp. 65-70, doi: 10.1109/CSPA.2019.8695976.

[22]. Islam, Mohammad Manzurul \& Morshed, Sarwar \& Goswami, Parijat. (2013). Cloud Computing: A Survey on its limitations and Potential Solutions. International Journal of Computer Science Issues. 10. 159-163.

[23]. Vukolic, Marko. (2010). The byzantine empire in the intercloud. SIGACT News. 41. 105-111. 10.1145/1855118.1855137.

[24]. Hong, Jiangshui \& Dreibholz, Thomas \& Schenkel, Joseph \& Hu, Jiaxi. (2019). An Overview of Multicloud Computing. 10.1007/978-3-030-15035-8_103. 